\title{
A Patient Decision Aid App for Patients With Chronic Kidney Disease: Questionnaire Study
}

Signe Bülow Therkildsen ${ }^{1}$, RN; Linda Houlind Hansen ${ }^{2}$, RN; Laura Emilie Dinesen Jensen ${ }^{3}$, RN; Jeanette Finderup ${ }^{4,5}$, DPhil

\footnotetext{
${ }^{1}$ Department of Orthopedics, Oslo University Hospital, Oslo, Norway

${ }^{2}$ Department of Nephrology, Odense University Hospital, Odense, Denmark

${ }^{3}$ Centre for Eating Disorders, Aarhus University Hospital, Aarhus, Denmark

${ }^{4}$ Department of Renal Medicine, Aarhus University Hospital, Aarhus, Denmark

${ }^{5}$ Department of Clinical Medicine, Aarhus University, Aarhus, Denmark
}

\author{
Corresponding Author: \\ Jeanette Finderup, DPhil \\ Department of Clinical Medicine \\ Aarhus University \\ Palle Juul-Jensens Boulevard 99 \\ Aarhus, 8200 \\ Denmark \\ Phone: 4578452525 \\ Email: jeajee@rm.dk
}

\begin{abstract}
Background: The Dialysis Guide (DG) is a patient decision aid (PDA) available as an app and developed for mobile phones for patients with chronic kidney disease facing the decision about dialysis modality.

Objective: The aim of this study was to uncover the applicability of the DG as a PDA.

Methods: The respondents completed a questionnaire before and after using the DG. The respondents' decisional conflicts were examined using the Decisional Conflict Scale, and the usability of the app was examined using the System Usability Scale (SUS). The change in decisional conflict was determined with a paired $t$ test.

Results: A total of 22 respondents participated and their mean age was 65.05 years; 20 out of 22 (90\%) had attended a patient school for kidney disease, and 13 out of $22(59 \%)$ had participated in a conversation about dialysis choice with a health professional. After using the DG, the respondents' decisional conflicts were reduced, though the reduction was not statistically significant $(P=.49)$. The mean SUS score was 66.82 (SD 14.54), corresponding to low usability.

Conclusions: The DG did not significantly reduce decisional conflict, though the results indicate that it helped the respondents decide on dialysis modality. Attending a patient school and having a conversation about dialysis modality choice with a health professional is assumed to have had an impact on the decisional conflict before using the DG. The usability of the DG was not found to be sufficient, which might be caused by the respondents' average age. Thus, the applicability of the DG cannot be definitively determined.
\end{abstract}

(JMIR Form Res 2019;3(4):e13786) doi: 10.2196/13786

\section{KEYWORDS}

mobile phone; app; patient decision aid; dialysis; decisional conflict; usability

\section{Introduction}

This paper sheds light on the applicability of a patient decision aid (PDA), the Dialysis Guide (DG) [1], which is available as an app for mobile phones and is made in accordance with the International Patient Decision Aid Standards (IPDAS) [2]. The $\mathrm{DG}$ is for patients with chronic kidney disease facing the choice of dialysis modality. The DG is a further development of a PDA in paper format, currently used at four hospitals in Denmark [3].

According to IPDAS, the purpose of a PDA is to improve the quality of decisions to enable patients to make informed, value-based decisions [4]. PDAs must make the decision 
explicit, contain information, and clarify advantages and disadvantages. The aim is to create agreement between the decision and individual values and preferences [5]. PDAs contribute to reduction of decisional conflicts and positively affect patients' basis for making a decision [6]. Some PDAs have been developed for patients with chronic kidney disease; however, studies of the effects of PDAs are few [7]. Thus, it is relevant to measure whether the DG reduces patients' decisional conflicts and helps them decide.

A systematic literature search was performed in the Cumulative Index of Nursing and Allied Health Literature (CINAHL) and PubMed databases to identify evaluated PDAs in app format; one PDA in app format for iPads was found [8]. Multiple studies regarding the assessment of online PDAs were also found. Grey literature searches in The Ottawa Hospital Research Institute's database [9] and the Facebook group Shared@ Shared Decision-Making Network supported this, and one more PDA in app format for mobile phones was found [10]. Only a few studies about PDAs in app format were found; none of them covered choice of dialysis modality.

Mobile apps have become easily accessible. In 2017, $84 \%$ of Danish families had a mobile phone [11]. Thus, it can be questioned why there are so few PDAs in app format. This is supported by the concept telemedicine, which, according to the World Health Organization, includes Web-based apps. The aim of telemedicine is to improve health results and provide clinical support through the use of information and communication technology across physical and geographical barriers [12]. The European Commission regards telemedicine as a solution to demographic changes with more elderly patients and, thus, more chronic diseases [13]. It is important to consider the advantages and disadvantages of apps [14]. The app format makes it easy to update PDAs and the material is always easily accessible. However, not all patients will necessarily benefit from PDAs in the app format. Moreover, patients with no access to technology, as well as the elderly with limited technological knowledge, may find apps less beneficial [15]. A PDA for dialysis choice was required by the Renal Association in Denmark; this was a request made by the patients.

The aim of this study was to examine whether the app, the DG, is applicable as a PDA for patients with chronic kidney disease to decide on dialysis modality. The following hypotheses were made:

Hypothesis 1: The DG reduces the patient's decisional conflicts.

Hypothesis 2: The DG has a high level of usability.

\section{Methods}

\section{Study Design}

Initially, we made a qualitative pilot study to adjust the DG. After this, a quantitative study design was used. This study design was developed as a hypothetico-deductive, cross-sectional study where data were collected through a preand postintervention questionnaire and used to examine the applicability of the DG. The method for assessing the DG was supported by the available literature [8,16-21].

\section{The Dialysis Guide}

The purpose of the DG is to support patients to clarify their values when choosing dialysis modality. The DG includes information and a test. The information focuses on kidney failure, dialysis choice, and dialysis modalities, and the app has a glossary (see Figure 1).

Figure 1. Screenshot of the Dialysis Guide index.

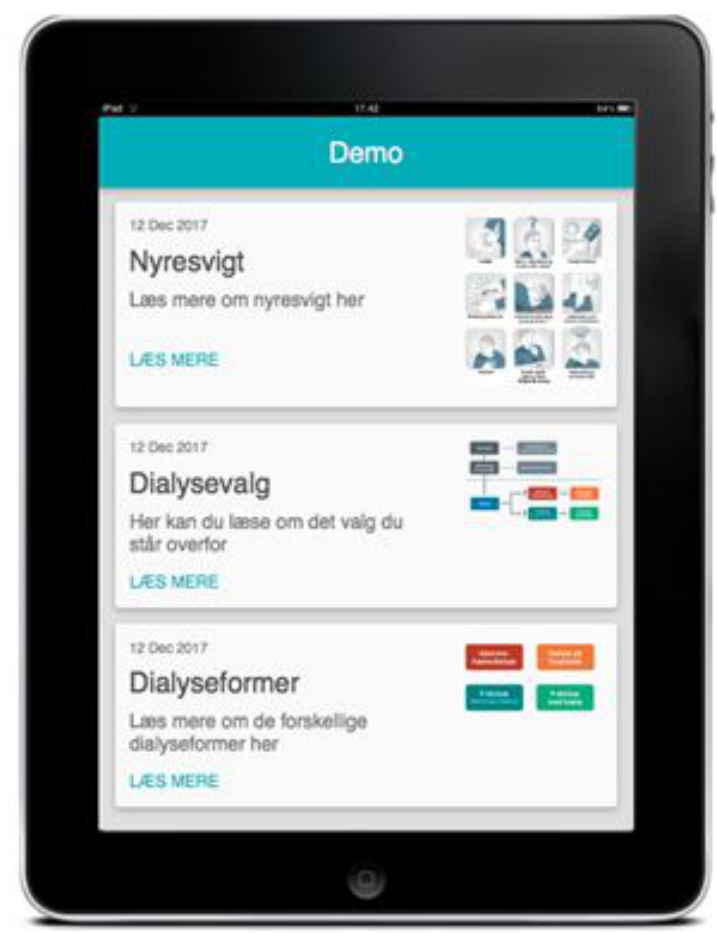


The dialysis modalities to choose from include home hemodialysis, peritoneal dialysis, peritoneal dialysis with help, or hemodialysis at hospital. The test contains 11 questions to match the advantages and disadvantages of the different dialysis modalities to the patient's preferences for each dialysis modality (see Figure 2). The individual patient's test result is presented in the end.

Figure 2. Screenshot of the Dialysis Guide test.

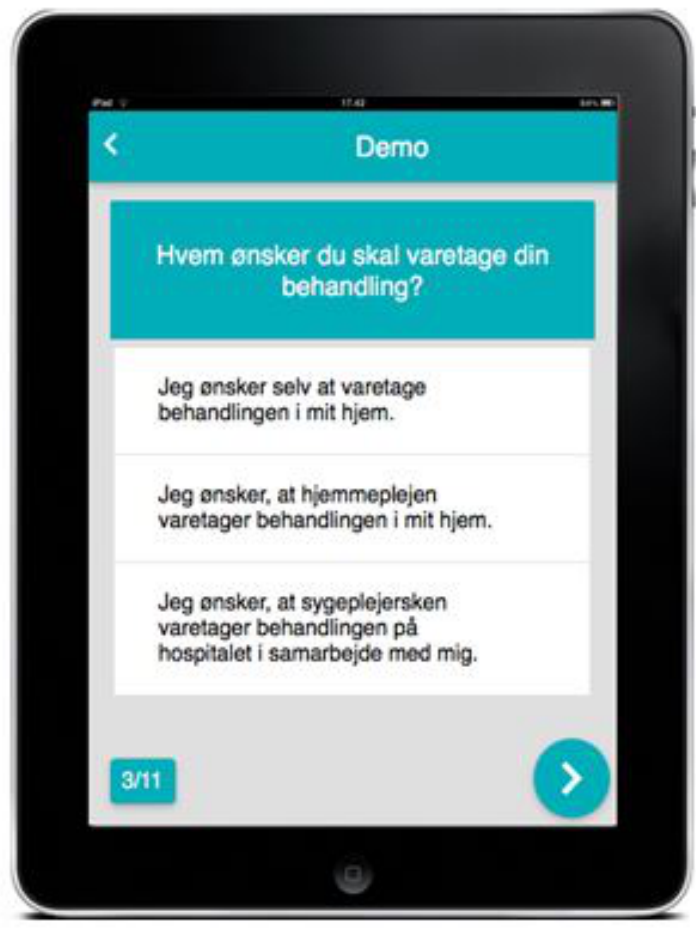

\section{Technical Development}

The DG is a responsive front-end Web app developed in HTML5. The front end communicates via http and JavaScript Object Notation (JSON) with a server-based back end, which is based on Drupal content management system (CMS), version 7.38 (Dries Buytaert). This is used to administer all the content published in the front-end app. The back end is executed via a Linux-based (The Linux Foundation) Apache Web server (The Apache Software Foundation) that runs a Hypertext Preprocessor (PHP), version 7.0.26 (The PHP Group), with two attached database servers that run the MySQL (Structured Query Language), version 5.7.20 (Oracle Corporation) [22].

\section{Pilot Study}

The pilot study was performed as two focus groups aimed at acquiring new knowledge [23]. These took place in September and October 2017 in two Danish regions; 6 and 11 patients participated, respectively. They were conducted by the second author in accordance with Kvale and Brinkmann [24]. Data analysis was conducted by all authors using systematic text condensation [25].

We found that the informants' ages and the severities of the disease were significant for a patient's approach to the DG. Some experienced that the DG was introduced too early in their disease trajectory. Multiple informants stated that apps were not for the elderly. Furthermore, several participants expressed a lack of time to try out the app. The DG information was found relevant and easy to understand. Constructive feedback in relation to the wording of some questions in the test was also given. In addition, a regional difference in the motivation for the use of the app was identified. The findings were used to adjust the DG as well as to construct the demographic questions for the evaluation of the app.

\section{Selection of Respondents}

People aged 18 years or older with chronic kidney disease and an estimated glomerular filtration rate (eGFR) between 10 and $20 \mathrm{~mL} / \mathrm{min} / 1.73 \mathrm{~m}^{2}$ were included in the study. Patients unable to read and understand Danish, who did not use electronic devices, or with cognitive deficits were excluded. Likewise, patients who had previously received dialysis or who had already started dialysis were also excluded. Respondents were recruited by nurses from eight of 14 renal departments in Denmark between November 23, 2017, and June 30, 2018. The nurses informed the patients about the study and obtained patients' email addresses. The questionnaires were subsequently forwarded to the patients by email, including a link to the DG.

\section{Decisional Conflict}

To clarify whether the DG reduced patients' decisional conflicts, the validated 16-statement Decisional Conflict Scale (DCS) was used. The scale uses a 5-point Likert scale from 0 (Strongly agree) to 4 (Strongly disagree) [26,27]. The scale measures whether the PDA facilitates effective decision making as well as insecurities in relation to decision making [28]. SurveyXact (Rambøll) [29] was used for data collection. The preintervention questionnaire contained demographic questions (ie, age, gender, region, participation in a conversation regarding dialysis choice, and participation in a patient school) and measured the 
respondents' decisional conflicts using the DCS (DCS1). The respondents were recommended to use the DG for 20 minutes before they completed the postintervention questionnaire. Then, the respondents' decisional conflicts were measured again using the DCS (DSC2). The data analysis was performed using Excel (Microsoft Corporation) [30]. The means and SDs were calculated for the DCS. The results for DCS1 and DCS2 were compared using a paired $t$ test. Data obtained from the DCS were rated using a total score between 0 and 100. In the DCS, a score of 0 is considered as no decisional conflict, a score of 100 is considered as an extremely high degree of decisional conflict, and a score lower than 25 is associated with making a decision. The subscores-Uncertainty, Information, Values Clarity, Support, and Effective Decision-were calculated [31].

\section{Usability}

To assess the usability of the DG, the System Usability Scale (SUS) was used. The SUS consists of 10 questions that also use a 5-point Likert scale from 1 (Strongly disagree) to 5 (Strongly agree) [32]. The scale was chosen as it was validated and developed to assess the usability of software [33].

Data were collected postintervention. Data obtained from the SUS were rated using a total score between 0 and 100, and means and SDs were calculated. In the SUS, a score of 0 is considered a low degree of usability and a score of 100 as a high degree of usability. A score above 68 is higher than the average SUS score and a score of 76 shows good usability [33].
The individual questions in the SUS were presented with the percentage of answers spread between the different choices on the Likert scale.

\section{Ethical Considerations}

The Central Denmark Region Committee on Health Research Ethics [34] and The Danish Data Protection Agency [35] have approved this study. All involved patients have given informed consent. Data were anonymized, safely stored, and shredded after use.

\section{Results}

\section{Participant Flow and Characteristics}

A total of 33 respondents were recruited; $28(85 \%)$ of those completed the preintervention questionnaire and $22(67 \%)$ also completed the postintervention questionnaire. Only the respondents who completed both questionnaires were included $(22 / 33,67 \%$ ) (see Table 1). The mean age of the respondents was 65.06 years; 15 respondents were men $(68 \%)$ and 7 were women $(32 \%)$. Respondents from three out of five regions in Denmark were represented. A total of 20 out of 22 respondents $(91 \%)$ had already attended a patient school, while 13 out of 22 $(59 \%)$ had participated in a conversation about dialysis choice. Three electronic devices were used in the study: 12 out of 22 participants $(55 \%)$ used a mobile phone, 5 out of $22(23 \%)$ used an iPad or tablet, and 5 out of $22(23 \%)$ used a computer.

Table 1. Demographic characteristics $(\mathrm{N}=22)$.

\begin{tabular}{|c|c|}
\hline Characteristics & Value \\
\hline Age (years), mean (range) & $65.05(44-86)$ \\
\hline \multicolumn{2}{|l|}{ Gender, n (\%) } \\
\hline Female & $7(32)$ \\
\hline Male & $15(68)$ \\
\hline \multicolumn{2}{|l|}{ Region, $\mathbf{n}(\%)$} \\
\hline North Denmark Region & $0(0)$ \\
\hline Central Denmark Region & $10(45)$ \\
\hline Region of Southern Denmark & $0(0)$ \\
\hline Region Zealand & $1(5)$ \\
\hline Capital Region of Denmark & $11(50)$ \\
\hline \multicolumn{2}{|l|}{ Attended patient school, n (\%) } \\
\hline Yes & $20(91)$ \\
\hline No & $2(9)$ \\
\hline \multicolumn{2}{|c|}{ Attended a conversation about dialysis with a health practitioner, $n(\%)$} \\
\hline Yes & $13(59)$ \\
\hline No & $9(41)$ \\
\hline \multicolumn{2}{|l|}{ Electronic device used, n (\%) } \\
\hline Mobile phone & $12(55)$ \\
\hline iPad or tablet & $5(23)$ \\
\hline Computer & $5(23)$ \\
\hline
\end{tabular}




\section{Decisional Conflict}

A comparison of the results for DCS1 and DCS2 showed a difference in mean values and SDs (see Table 2). For DCS1, the total mean decisional conflict was 26.42 (SD 18.12) and for DCS2 the mean was 25.21 (SD 16.93). Thus, no significantly reduced decisional conflict was found (paired $t$ test: difference=-1.21, $P=.49$ ). The remaining subscores were not significant either. The respondents' DCS1 scores for Information and Support were lower than 25, which was also the case for DCS2. The Uncertainty subscore was reduced the most with a fall of 3.41. Both the Values Clarity subscore and the Support subscore were higher after use of the DG.

The total mean for decisional conflicts was lower for respondents who had attended a conversation about dialysis choice before using the DG, while it was only reduced for those who had not attended one (see Table 3). The women's mean decisional conflict was lower compared to that of the men. The women's mean decisional conflict rose after having used the DG, whereas it was reduced among the men.

Table 2. Changes from preintervention Decisional Conflict Scale (DCS1) to postintervention Decisional Conflict Scale (DCS2) (N=22).

\begin{tabular}{lllll}
\hline Score & DCS1, mean (SD) & DCS2, mean (SD) & Difference (paired $t$ test) & $P$ value \\
\hline Total score & $26.42(18.12)$ & $25.21(16.93)$ & -1.21 & .49 \\
Uncertainty subscore & $30.30(24.87)$ & $26.89(19.57)$ & -3.41 & .13 \\
Informed subscore & $22.73(14.13)$ & $21.97(15.97)$ & -0.76 & .67 \\
Values Clarity subscore & $25.38(18.81)$ & $28.03(18.64)$ & 2.65 & .41 \\
Support subscore & $21.14(17.45)$ & $21.97(18.10)$ & 0.83 & .83 \\
Effective Decision subscore & $29.26(21.42)$ & $26.70(19.88)$ & -2.56 & .29 \\
\hline
\end{tabular}

Table 3. The meaning of demography for the Decisional Conflict Scale.

\begin{tabular}{lll}
\hline Demographic & DCS1 $^{\mathrm{a}}$ total score, mean (SD) & DCS2 ${ }^{\mathrm{b}}$ total score, mean (SD) \\
\hline Attended a conversation about dialysis with a health practitioner & $20.67(9.38)$ & $21.75(9.85)$ \\
Did not attend a conversation about dialysis with a health practitioner & $34.72(24.47)$ & $31.60(22.72)$ \\
Male & $29.02(15.91)$ & $27.15(13.71)$ \\
Female & $20.76(22.48)$ & $20.98(23.14)$ \\
\hline
\end{tabular}

${ }^{\mathrm{a} D C S 1:}$ preintervention Decisional Conflict Scale.

${ }^{\mathrm{b}}$ DCS2: postintervention Decisional Conflict Scale.

\section{Usability}

The majority of the answers to the individual questions in the SUS ranged from 2 to 4 on the Likert scale. The mean for the overall SUS score was 66.82 (SD 14.54). The average SUS scores for the individual devices were 69.58 for mobile phones, 66.00 for iPads or tablets, and 61.00 for computers. See Table 4 for a summary of SUS response scores for each question. 
Table 4. System Usability Scale (SUS) answers (N=22).

\begin{tabular}{|c|c|c|c|c|c|}
\hline \multirow[t]{2}{*}{ Question } & \multicolumn{5}{|l|}{ Response, n (\%) } \\
\hline & Strongly disagree & Disagree & $\begin{array}{l}\text { Neither agree nor } \\
\text { disagree }\end{array}$ & Agree & Strongly agree \\
\hline I think that I would like to use the Dialysis Guide frequently & $1(5)$ & $0(0)$ & $7(32)$ & $11(50)$ & $3(14)$ \\
\hline I found the Dialysis Guide unnecessarily complex & $2(9)$ & $7(32)$ & $11(50)$ & $2(9)$ & $0(0)$ \\
\hline I thought the Dialysis Guide was easy to use & $7(32)$ & $3(14)$ & $8(36)$ & $4(18)$ & $0(0)$ \\
\hline $\begin{array}{l}\text { I think that I would need the support of a technical person to } \\
\text { use the Dialysis Guide }\end{array}$ & $1(5)$ & $0(0)$ & $5(23)$ & $14(64)$ & $2(9)$ \\
\hline $\begin{array}{l}\text { I found the various functions in the Dialysis Guide were well } \\
\text { integrated }\end{array}$ & $2(9)$ & $10(45)$ & $8(36)$ & $1(5)$ & $1(5)$ \\
\hline $\begin{array}{l}\text { I thought there was too much inconsistency in the Dialysis } \\
\text { Guide }\end{array}$ & $2(9)$ & $10(45)$ & $8(36)$ & $1(5)$ & $1(5)$ \\
\hline $\begin{array}{l}\text { I would imagine that most people would learn to use the } \\
\text { Dialysis Guide very quickly }\end{array}$ & $0(0)$ & $2(9)$ & $4(18)$ & $13(59)$ & $3(14)$ \\
\hline I found the Dialysis Guide very cumbersome to use & $5(23)$ & $10(45)$ & $7(32)$ & $0(0)$ & $0(0)$ \\
\hline I felt very confident using the Dialysis Guide & $0(0)$ & $1(5)$ & $7(32)$ & $8(36)$ & $6(27)$ \\
\hline $\begin{array}{l}\text { I needed to learn a lot of things before I could get going with } \\
\text { the Dialysis Guide }\end{array}$ & $4(18)$ & $5(23)$ & $8(36)$ & $5(23)$ & $0(0)$ \\
\hline
\end{tabular}

\section{Discussion}

The reduction of the respondents' decisional conflicts as a result of using the DG was not significant. Thus, it is difficult to determine the extent to which the DG can help patients make a decision regarding the choice of dialysis modality. Therefore, it cannot be concluded that the DG meets the purpose of PDAs described by IPDAS, which is to improve the quality of decisions to facilitate informed and value-based decisions [3].

The usability of the DG is problematic because of the low number of respondents and their different answers in the SUS, with scores mainly around the middle of the Likert scale. Therefore, it cannot be confirmed that the DG has a high degree of usability. Likewise, it was difficult to shed light on the applicability of the app format for mobile phones, as all three types of devices were represented.

The results for the subscores in the DCS were not significant either, which might be due to the low number of respondents. However, the results indicated that the respondents received sufficient information, experienced an improved decision quality, and were less uncertain about their decision. In the evaluation of a similar PDA in paper format, the patients obtained an increased knowledge of the different dialysis modalities and became more prepared to make a decision [36]. This is in line with our study, as indications suggest that the DG improved respondents' levels of information as well as reduced their uncertainty.

The Information and Support subscores were below 25 in DCS1, which indicate that the patients had already received sufficient information and aid in making their decisions about dialysis modality before use of the DG [27]. Therefore, it is doubtful that these subscores could be reduced further through the use of the DG. However, a minor reduction of the Information subscore was seen. Already prior to using the DG, the respondents' decisional conflicts neared 25 . This can be explained by the fact that $91 \%$ had participated in a patient school before using the DG. As the Information subscore in DCS1 was low, it is assumed that the respondents had received adequate information at the patient schools to make a decision. In other studies, it was also found that patients with chronic kidney disease who had already been educated on the subject had a lower degree of decisional conflict than patients who had not received any information $[37,38]$. One of the studies supports the notion that information at a patient school may have an impact on the applicability of a PDA. Whether or not patients had been exposed to a PDA-beyond being exposed to information-we found that the DG did not have an impact on patients' decisional conflicts. It was also found that decisional conflict only appeared among those respondents who had not yet had a conversation with a professional about dialysis choice [38]. This could indicate that the DG is mainly applicable for patients faced with the choice of dialysis modality, but who had not yet received information at a patient school or discussed dialysis choice with a professional.

Prior to use of the DG, the female respondents had a decisional conflict below 25 . This indicates that they had already decided on a type of dialysis at this point [27]. On the other hand, the men had not decided on their choice before use of the DG, but their decisional conflict was reduced after its use. This indicates that the DG helped the men become more confident in making a decision. However, another study on significant factors for decisional conflict when choosing dialysis modality did not find that gender was a factor regarding decisional conflict [37].

The mean for the total SUS score was below the average SUS score, but the mean value when using a mobile phone was above this average score. Usability is considered highest when using a mobile phone, which is in contrast to a study evaluating a PDA for an iPad. Here, usability was higher on an iPad, as the size of the screen was bigger [8]. So far, there are only few 
PDAs in app format for mobile phones. However, examples of patients finding PDAs for mobile phones usable and easy to navigate exist [10]. It is also presumed that a high degree of usability can be achieved for PDAs for mobile phones. However, the patients who used these had extensive knowledge of mobile phones, which might have impacted on the high usability $[39,40]$. This could also be the case in this study, as the respondents who chose to use a mobile phone would most likely choose it because they were familiar with this device.

The mean age for the respondents was 65.05 years, which is similar to the patient population's mean age in the Danish Nephrology Registry's Annual Report, 2016 [41]. It is presumed that the mean age may have an impact on the assessed usability of the DG, as the cognitive and physical abilities of older and younger participants differ. This may influence the older participants' use of Web-based telemedicine solutions [42]. In another study, researchers found that the usability of an online PDA was higher for patients under the age of 36 years [19].

The limitations of this study make it difficult to assess the applicability of the DG. The method of distribution entailed a weakness as it was not possible to make a dropout analysis. The number of respondents and the low response rate was also a weakness. The reason for the low number of respondents might be the lack of recruitment from some of the invited renal departments. Doubts about the validity of some of the email addresses might have impacted on the response rate. In other studies evaluating the use of PDAs in the same patient group, a response rate of $70 \%$ or lower was also seen $[38,43]$. One of these studies described that the nurses' recruitment of patients might be important to the outcome [36]. The nurses' approach to, and presentation of, the PDA may also have an impact on patients' views of the applicability [10]. Despite the inclusion and exclusion criteria, the nurses' subjective recruitment might have impacted on the results. The low number of respondents and low recruitment could mean that not all Danish regions were represented; therefore, it was not possible to assess whether the geographical location had an impact on the respondents' answers. Despite the recommended time for using the DG, not knowing how long the individual respondents used the app was a limitation.

On the basis of this study, it cannot be definitively concluded that the DG is applicable as a PDA for patients with chronic kidney disease deciding on dialysis modality. The DG did not reduce respondents' decisional conflicts significantly. Hence, Hypothesis 1 cannot be confirmed. However, a reduction of respondents' decisional conflicts was seen after use of the DG, but indications suggest that this is limited if the patient had received information at a patient school or attended a conversation about dialysis choice with a professional beforehand.

It can be concluded that the usability of the DG is not sufficiently clarified at present, which means that Hypothesis 2 is disproved. The low usability might be a result of the respondents' mean age. However, the usability was assessed as higher when using a mobile phone.

The limited knowledge about PDAs in app format and the number of respondents in this study mean that there is a need for further research to determine the applicability of the DG. It might be relevant to examine the difference between the applicability of PDAs in paper and app formats in a randomized controlled trial. If the DG is to be used in shared decision making, it is also relevant to examine the health professional's view of the applicability of the DG.

\section{Conflicts of Interest}

None declared.

\section{References}

1. The Dialysis Guide. URL: http://dialysetest.dk.linux69.unoeuro-server.com/www/ [accessed 2019-11-13]

2. International Patient Decision Aid Standards (IPDAS) Collaboration. URL: http://ipdas.ohri.ca/ [accessed 2017-11-13]

3. Finderup J, Jensen JKD, Lomborg K. Developing and pilot testing a shared decision-making intervention for dialysis choice. J Ren Care 2018 Sep;44(3):152-161. [doi: 10.1111/jorc.12241] [Medline: 29664179]

4. International Patient Decision Aid Standards (IPDAS) Collaboration. URL: http://ipdas.ohri.ca/what.html [accessed 2017-11-07]

5. Thompson R, Trevena L. Demystifying decision aids: A practical guide for clinicians. In: Elwyn G, Edwards A, Thompson R, editors. Shared Decision Making in Health Care: Achieving Evidence-Based Patient Choice. 3rd edition. Oxford, UK: Oxford University Press; 2016:51-56.

6. Stacey D, Légaré F, Lewis K, Barry MJ, Bennett CL, Eden KB, et al. Decision aids for people facing health treatment or screening decisions. Cochrane Database Syst Rev 2017 Apr 12;4:CD001431 [FREE Full text] [doi: 10.1002/14651858.CD001431.pub5] [Medline: 28402085]

7. Davis JL, Davison SN. Hard choices, better outcomes. Curr Opin Nephrol Hypertens 2017;26(3):205-213. [doi: 10.1097/mnh.0000000000000321]

8. Eden KB, Scariati P, Klein K, Watson L, Remiker M, Hribar M, et al. Mammography decision aid reduces decisional conflict for women in their forties considering screening. J Womens Health (Larchmt) 2015 Dec;24(12):1013-1020 [FREE Full text] [doi: 10.1089/jwh.2015.5256] [Medline: 26360918]

9. Ottawa Hospital Research Institute. Patient decision aids: Alphabetical list of decision aids by health topic URL: https:/ /decisionaid.ohri.ca/AZlist.html [accessed 2017-09-20] 
10. Korsbek L, Tønder ES. Momentum: A smartphone application to support shared decision making for people using mental health services. Psychiatr Rehabil J 2016 Jun;39(2):167-172. [doi: 10.1037/prj0000173] [Medline: 27030907]

11. Statistics Denmark. Home appliances URL: http://www.dst.dk/en/Statistik/emner/priser-og-forbrug/forbrug/ elektronik-i-hjemmet [accessed 2019-11-13]

12. Telemedicine: Opportunities and Developments in Member States. Report on the Second Global Survey on eHealth. Geneva, Switzerland: World Health Organization; 2010. URL: https://www.who.int/goe/publications/goe telemedicine 2010.pdf [accessed 2019-11-13]

13. Telemedicine for the Benefit of Patients, Healthcare Systems and Society. Brussels, Belgium: European Commission; 2009 Jun. URL: http://www.cupid-project.eu/sites/default/files/

Staffworkingpaper-Telemedicineforthebenefitofpatientshealthcaresystemsandsociety.pdf [accessed 2017-11-09]

14. Mosa AS, Yoo I, Sheets L. A systematic review of healthcare applications for smartphones. BMC Med Inform Decis Mak 2012 Jul 10;12:67 [FREE Full text] [doi: 10.1186/1472-6947-12-67] [Medline: 22781312]

15. Abbasgholizadeh Rahimi S, Menear M, Robitaille H, Légaré F. Are mobile health applications useful for supporting shared decision making in diagnostic and treatment decisions? Glob Health Action 2017 Jun;10(sup3):1332259 [FREE Full text] [doi: 10.1080/16549716.2017.1332259] [Medline: 28838306]

16. Van Scoy LJ, Green MJ, Dimmock AE, Bascom R, Boehmer JP, Hensel JK, et al. High satisfaction and low decisional conflict with advance care planning among chronically ill patients with advanced chronic obstructive pulmonary disease or heart failure using an online decision aid: A pilot study. Chronic Illn 2016 Sep;12(3):227-235. [doi: 10.1177/1742395316633511] [Medline: 27055468]

17. Sivell S, Edwards A, Manstead AS, Reed MW, Caldon L, Collins K, BresDex Group. Increasing readiness to decide and strengthening behavioral intentions: Evaluating the impact of a Web-based patient decision aid for breast cancer treatment options (BresDex: www.bresdex.com). Patient Educ Couns 2012 Aug;88(2):209-217. [doi: 10.1016/j.pec.2012.03.012] [Medline: 22541508]

18. Hoffman AS, Llewellyn-Thomas HA, Tosteson AN, O'Connor AM, Volk RJ, Tomek IM, et al. Launching a virtual decision lab: Development and field-testing of a Web-based patient decision support research platform. BMC Med Inform Decis Mak 2014 Dec 12;14:112 [FREE Full text] [doi: 10.1186/s12911-014-0112-8] [Medline: 25495552]

19. Schackmann EA, Munoz DF, Mills MA, Plevritis SK, Kurian AW. Feasibility evaluation of an online tool to guide decisions for BRCA1/2 mutation carriers. Fam Cancer 2013 Mar;12(1):65-73 [FREE Full text] [doi: 10.1007/s10689-012-9577-8] [Medline: 23086584]

20. Wakefield CE, Watts KJ, Meiser B, Sansom-Daly U, Barratt A, Mann GJ, et al. Development and pilot testing of an online screening decision aid for men with a family history of prostate cancer. Patient Educ Couns 2011 Apr;83(1):64-72. [doi: 10.1016/j.pec.2010.05.025] [Medline: 20580521]

21. van Til JA, Drossaert CH, Renzenbrink GJ, Snoek GJ, Dijkstra E, Stiggelbout AM, et al. Feasibility of Web-based decision aids in neurological patients. J Telemed Telecare 2010;16(1):48-52. [doi: 10.1258/jtt.2009.001012] [Medline: 20086268]

22. MinMenu. URL: http://www.movesca.com/ [accessed 2019-11-23]

23. Halkier B. Planlægning af fokusgrupper. In: Kjølby A, Møllerhøj AB, editors. Fokusgrupper. 3rd edition. Frederiksberg C, Denmark: Samfundslitteratur; 2016:23.

24. Kvale S, Brinkmann S. Transcribing interviews. In: InterViews: Learning the Craft of Qualitative Research Interviewing. 3rd edition. Thousand Oaks, CA: SAGE Publications; 2015:203-214.

25. Malterud K. Systematic text condensation: A strategy for qualitative analysis. Scand J Public Health 2012 Dec;40(8):795-805. [doi: 10.1177/1403494812465030] [Medline: 23221918]

26. O'Connor AM. Validation of a decisional conflict scale. Med Decis Making 2016 Jul 02;15(1):25-30. [doi: 10.1177/0272989x9501500105]

27. O'Connor AM. Ottawa Hospital Research Institute. 1993. Decisional conflict scale URL: https://decisionaid.ohri.ca/docs/ develop/Tools/DCS Danish.pdf [accessed 2019-11-13]

28. Ottawa Hospital Research Institute. Patient decision aids: Decisional conflict scale URL: https://decisionaid.ohri.ca/eval_des. $\underline{\mathrm{html}}$ [accessed 2019-11-13]

29. SurveyXact. URL: https://www.surveyxact.dk/ [accessed 2019-11-13]

30. Microsoft Office. Microsoft Excel URL: https://products.office.com/en-gb/excel [accessed 2019-11-13]

31. O'Connor AM. Ottawa Hospital Research Institute. 1993. User manual: Decisional conflict scale URL: https://decisionaid. ohri.ca/docs/develop/User Manuals/UM Decisional Conflict.pdf [accessed 2019-11-13]

32. Brooke J. SUS: A Quick and Dirty Usability Scale. Reading, UK: Digital Equipment Corporation; 1986. URL: http:/ /citeseerx.ist.psu.edu/viewdoc/download?doi=10.1.1.232.5526\&rep=rep1\&type=pdf [accessed 2019-11-13]

33. Sauro J. A Practical Guide to the System Usability Scale: Background, Benchmarks \& Best Practices. Denver, CO: Measuring Usability; 2011.

34. National Vidensskabetisk Komité. URL: http://www.nvk.dk/ [accessed 2019-11-13]

35. Datatilsynet. Om Datatilsynet URL: https://www.datatilsynet.dk/om-datatilsynet/ [accessed 2019-11-13]

36. Prichard A, Thomas N. The option grid: A shared decision-making tool for renal patients. J Ren Nurs 2013 Jan;5(1):6-11. [doi: 10.12968/jorn.2013.5.1.6] 
37. Chen N, Lin Y, Liang S, Tung H, Tsay S, Wang T. Conflict when making decisions about dialysis modality. J Clin Nurs 2018 Jan;27(1-2):e138-e146. [doi: 10.1111/jocn.13890] [Medline: 28543737]

38. Winterbottom AE, Gavaruzzi T, Mooney A, Wilkie M, Davies SJ, Crane D, et al. Patient acceptability of the Yorkshire Dialysis Decision Aid (YoDDA) booklet: A prospective non-randomized comparison study across 6 predialysis services. Perit Dial Int 2016;36(4):374-381 [FREE Full text] [doi: 10.3747/pdi.2014.00274] [Medline: 26429419]

39. Wood J, Jenkins S, Putrino D, Mulrennan S, Morey S, Cecins N, et al. High usability of a smartphone application for reporting symptoms in adults with cystic fibrosis. J Telemed Telecare 2017 Aug 11;24(8):547-552. [doi: 10.1177/1357633x17723366]

40. Zia J, Schroeder J, Munson S, Fogarty J, Nguyen L, Barney P, et al. Feasibility and usability pilot study of a novel irritable bowel syndrome food and gastrointestinal symptom journal smartphone app. Clin Transl Gastroenterol 2016 Mar 03;7:e147 [FREE Full text] [doi: 10.1038/ctg.2016.9] [Medline: 26938478]

41. Danish Nephrology Registry (DNR): Nationwide Database for Patients With Chronic Renal Failure. Annual Report 2016. Copenhagen, Denmark: Danish Society of Nephrology; 2017. URL: http://nephrology.dk/wp-content/uploads/2017/08/ \%C3\%85rsrapport-2016.pdf [accessed 2019-11-13]

42. Chun Y, Patterson P. A usability gap between older adults and younger adults on interface design of an Internet-based telemedicine system. Work 2012;41 Suppl 1:349-352. [doi: 10.3233/WOR-2012-0180-349] [Medline: 22316747]

43. Fortnum D, Grennan K, Smolonogov T. End-stage kidney disease patient evaluation of the Australian 'My Kidneys, My Choice' decision aid. Clin Kidney J 2015 Aug;8(4):469-475 [FREE Full text] [doi: 10.1093/ckj/sfv050] [Medline: 26251720]

\author{
Abbreviations \\ CINAHL: Cumulative Index of Nursing and Allied Health Literature \\ CMS: content management system \\ DCS: Decisional Conflict Scale \\ DCS1: preintervention Decisional Conflict Scale \\ DCS2: postintervention Decisional Conflict Scale \\ DG: Dialysis Guide \\ eGFR: estimated glomerular filtration rate \\ IPDAS: International Patient Decision Aid Standard \\ JSON: JavaScript Object Notation \\ PDA: patient decision aid \\ PHP: Hypertext Preprocessor \\ SQL: Structured Query Language \\ SUS: System Usability Scale
}

\author{
Edited by G Eysenbach; submitted 22.02.19; peer-reviewed by D Schatell, R Ciptaningtyas; comments to author 09.10.19; revised \\ version received 22.10.19; accepted 31.10.19; published 21.11.19 \\ Please cite as: \\ Therkildsen SB, Hansen LH, Jensen LED, Finderup J \\ A Patient Decision Aid App for Patients With Chronic Kidney Disease: Questionnaire Study \\ JMIR Form Res 2019;3(4):e13786 \\ URL: http://formative.jmirorg/2019/4/e13786/ \\ doi: 10.2196/13786 \\ PMID: 31750836
}

CSigne Bülow Therkildsen, Linda Houlind Hansen, Laura Emilie Dinesen Jensen, Jeanette Finderup. Originally published in JMIR Formative Research (http://formative.jmir.org), 21.11.2019. This is an open-access article distributed under the terms of the Creative Commons Attribution License (https://creativecommons.org/licenses/by/4.0/), which permits unrestricted use, distribution, and reproduction in any medium, provided the original work, first published in JMIR Formative Research, is properly cited. The complete bibliographic information, a link to the original publication on http://formative.jmir.org, as well as this copyright and license information must be included. 